Paula Briggs, MBChB, FFSRH

Contraceptive Lead, May Logan Centre, Liverpool L20 5DQ, UK; paulaeb@aol.com

Competing interests None.

Provenance and peer review

Commissioned; internally peer reviewed.

J Fam Plann Reprod Health Care 2013;39:230. doi:10.1136/fprhc-2013-100640

\title{
REFERENCES
}

1 Holden SE. Comment on 'Impact of UK Medical Eligibility Criteria implementation on prescribing of combined hormonal contraceptives'. J Fam Plann Reprod Health Care 2013;39:229-230.

2 Briggs PE, Praet CA, Humphreys SC, et al. Impact of UK Medical Eligibility Criteria implementation on prescribing of combined hormonal contraceptives. J Fam Plann Reprod Health Care 2013;39:190-196.

\section{Comment on 'Impact of UK Medical Eligibility Criteria implementation on prescribing of combined hormonal contraceptives': author's response}

On behalf of all the authors I would like to thank Sarah Holden for her comments ${ }^{1}$ on our recently published article. ${ }^{2}$

When designing the study, we recognised that the majority of women receive their contraception from their general practitioner (GP). Our study compares the prescribing habits of GPs in 2005 pre-UK Medical Eligibility Criteria (pre-UKMEC) to those in 2010 (post-UKMEC).

Whilst the authors realise that this does not reflect total contraceptive usage in the UK, it does compare women prescribed combined hormonal contraceptives (CHCs) by their GPs in 2005 to a similar group of women in 2010. Consequently we presume that we are comparing 'apples' with 'apples' and therefore our conclusion that there was "a reduction in prescribing of $\mathrm{CHCs}$ to higher-risk women after publication of UKMEC, a large number of women with Category 3 or 4 risk factors are still prescribed CHCs" is valid and is worth publicising to the reproductive health clinical community. 